\title{
Quality assessment for processed and sterilized bone using Raman spectroscopy
}

\author{
Takeaki Yamamoto $\cdot$ Kentaro Uchida $\cdot$ Kouji Naruse $\cdot$ \\ Mitsutoshi Suto $\cdot$ Ken Urabe $\cdot$ Katsufumi Uchiyama $\cdot$ Kaori Suto • \\ Mitsutoshi Moriya $\cdot$ Moritoshi Itoman $\cdot$ Masashi Takaso
}

Received: 29 May 2011/Accepted: 29 August 2011/Published online: 8 September 2011

(C) The Author(s) 2011. This article is published with open access at Springerlink.com

\begin{abstract}
To eliminate the potential for infection, many tissue banks routinely process and terminally sterilize allografts prior to transplantation. A number of techniques, including the use of scanning electron microscopy, bone graft models, and mechanical property tests, are used to evaluate the properties of allograft bone. However, as these methods are time consuming and often destroy the bone sample, the quality assessment of allograft bones are not routinely performed after processing and sterilization procedures. Raman spectroscopy is a non-destructive, rapid analysis technique that requires only small sample volumes and has recently been used to evaluate the
\end{abstract}

T. Yamamoto $\cdot$ K. Uchida $(\bowtie) \cdot K$. Naruse .

K. Uchiyama · K. Suto · M. Moriya · M. Takaso

Department of Orthopaedic Surgery, Kitasato University

School of Medicine, 1-15-1 Kitasato, Minami-Ku,

Sagamihara, Kanagawa 252-0374, Japan

e-mail: kuchida@med.kitasato-u.ac.jp

M. Suto

Department of Orthopaedic Surgery, Moriya Daiichi

General Hospital, 1-17 Matsumaedai, Moriya-Shi,

Ibaraki 302-0102, Japan

K. Urabe

Department of Orthopaedic Surgery, Tsukui Red Cross

Hospital, 256 Nakano, Midori-ku, Sagamihara,

Kanagawa 252-0157, Japan

M. Itoman

Kyushu Rosai Hospital, 1-1 Sone-Kitamachi,

Kokura-Minami, Kitaksyushu, Fukuoka 800-0296, Japan mineral content, mineral crystallinity, acid phosphate and carbonate contents, and collagen maturity in human and animal bones. Here, to establish a quality assessment method of allograft bones using Raman spectroscopy, the effect of several common sterilization and preservation procedures on rat femoral bones were investigated. We found that freeze-thawing had no detectable effects on the composition of bone minerals or matrix, although heat treatment and gamma irradiation resulted in altered Raman spectra. Our findings suggest Raman spectroscopy may facilitate the quality control of allograft bone after processing and sterilization procedures.

Keywords Bone allograft · Raman spectroscopy · Sterilization · Quality assessment

\section{Introduction}

Bone grafts represent one of the earliest devised reconstructive approaches for the musculoskeletal system and remain among the most common orthopaedic procedures, being used for the repair of fractures, arthrodeses, and cystic defects, and skeletal deficits after traumatic loss or tumor resection.

To eliminate potential infection during allografting, many tissue banks routinely process and terminally sterilize allografts prior to transplantation. A number of techniques have evaluated the various 
properties of preserved and sterilized allograft bone, such as the use of scanning electron microscopy (SEM) for collagen structure (Voggenreiter et al. 1994), bone graft models for osteoinduction and bone absorption (Kühne et al. 1992), and compression or bending tests for mechanical properties (Anderson et al. 1992; Currey et al. 1997; Hamer et al. 1996; Nguyen et al. 2007). Although, these methods provide important information about the condition of allograft bone, they require lengthy assay periods or destruction of the bone; thus, bone tissues after processing and sterilization procedures are not evaluated prior to grafting. To permit the assessment of bone graft tissue, the development of more rapid and non-destructive evaluation methods has been needed.

Raman spectroscopy is a non-destructive, rapid analysis technique that requires only small sample volumes and is nearly resistant to interference from water. The spectroscopy technique has found wide application in biomedical fields and has recently been used to evaluate the mineral content, mineral crystallinity, acid phosphate and carbonate contents, and collagen maturity in human and animal bones (Akkus et al. 2004; Carden and Morris 2000; Freeman et al. 2001). As the frequency assignments for all major Raman spectral peaks of bone minera have been established, we speculated that Raman spectroscopy would be useful for the quality control of allograft bones after processing and sterilization procedures.

Here, to establish a quality assessment method of allograft bones using Raman spectroscopy, the effects of several common processing and sterilization procedures on rat femoral bones were investigated.

\section{Materials and methods}

Bone samples

The experimental protocol was approved by the animal care committee of Kitasato University School of Medicine. Femora were harvested from 8-weekold male Wistar rats (Charles River Japan, Inc., Yokohama, Japan), which were maintained at the animal facility of Kitasato University and fed rodent Diet CE-2 (CLEA Japan, Inc.), containing $1.18 \mathrm{~g}$ calcium and $1.03 \mathrm{~g}$ phosphorus $/ 100 \mathrm{~g}$ of feed. Bones collected from 36 rats were divided equally into the following 6 treatment groups: (1) Fresh, in which bones were untreated; (2) FT1, in which bones were frozen using an ultra-low temperature freezer at $-80^{\circ} \mathrm{C}$ (MDFU581; Sanyo Electric Co., Ltd., Osaka, Japan) for 6 weeks and then thawed at $37^{\circ} \mathrm{C}$ for $1 \mathrm{~h}$; (3) FT3, in which bones were subjected to three cycles of freezing for 2 weeks at $-80^{\circ} \mathrm{C}$ and then thawing at $37^{\circ} \mathrm{C}$ for $1 \mathrm{~h}$; (4) $60^{\circ} \mathrm{C}$, in which bones were heated at $60^{\circ} \mathrm{C}$ for $10 \mathrm{~h}$; (5) $80^{\circ} \mathrm{C}$, in which bones were heated at $80^{\circ} \mathrm{C}$ for $10 \mathrm{~min}$; and (6) Radi, in which bones were subjected to $25 \mathrm{kGy}$ cobalt- 60 gamma-irradiation. The excised and treated femoral bones were fixed for $48 \mathrm{~h}$ in $4 \%$ paraformaldehyde, which was then replaced with phosphate buffered saline (PBS), and the bones were then refrigerated at $4^{\circ} \mathrm{C}$ until Raman spectroscopy analyses.

\section{Confocal laser Raman spectroscopic measurements}

Confocal laser Raman microspectroscopy was used to determine the composition and relative intensities of bone minerals and matrix in the mid-shaft anterior cortex of the left femora $15 \mathrm{~mm}$ from the proximal end. Using a custom-made fixture, the proximal half of femora was placed on the microscope stage such that the transverse cross section at mid-shaft was oriented perpendicularly to the laser beam incident from a $80 \times$ microscope objective. Locations of interest were positioned with an accuracy of $0.1 \mu \mathrm{m}$ using a motorized XY stage and an optical camera. The intracortical compartment was subjected to measurements using a Nicolet Almega XR Dispersive Raman microscope system equipped with the OMNIC Atlus imaging software program (ThermoFisher Scientific, Inc., MA, USA). An area of less than $1 \mu^{2}$ can be mapped using Atlus software for samples visualized on the confocal video microscope. A high-brightness, low-intensity laser operating at $780 \mathrm{~nm}$ was used as the excitation source with a laser power of $35 \mathrm{~mW}$. Each spectrum shown is the sum of $10 \mathrm{~s}$ measurements. The peak areas or heights were calculated with the following Raman shift wavenumbers (Table 1): $\mathrm{PO}_{4}^{3-} v_{1}$, 981.9-925.7 $\mathrm{cm}^{-1} ; \mathrm{CH}_{2}$ wag, 1,446-1,455 $\mathrm{cm}^{-1}$; $\mathrm{PO}_{4}^{3-} \quad v_{4}, 631.0-545.8 \mathrm{~cm}^{-1} ; \mathrm{CO}_{3}^{2-} v_{1}, 1,087.9-$ $1,052.1 \mathrm{~cm}^{-1}$; amide I, 1,716.3-1,541.2 $\mathrm{cm}^{-1}$; amide III, 1,298.1-1,214.4 $\mathrm{cm}^{-1}$; hydroxyproline, 855 and $878 \mathrm{~cm}^{-1}$; and proline, $919 \mathrm{~cm}^{-1}$; as described in Akkus et al. (2004). Crystallinity, a parameter of mineral maturation, was determined as the inverse of 
the width of the phosphate symmetric-stretch band $\left(\mathrm{PO}_{4}^{3-} v_{1}\right.$ at $\left.959 \mathrm{~cm}^{-1}\right)$ at half the maximum intensity value, as previously described (Yerramshetty and Akkus 2008).

\section{Statistical analysis}

Data were summarized to allow comparisons between the Fresh and other five treatment groups. All data values are expressed as the mean \pm standard deviation (SD). The group means were compared by one-way analysis of variance (ANOVA) followed by Tukey's HSD post-hoc multiple comparison tests using a commercially available statistical package (SPSS $11.0 \mathrm{~J}$ for Windows; SPSS, Inc., Tokyo, Japan).

\section{Results}

Raman spectral analysis of the anterior cortex of rat femora in the treatment group revealed the resolvable mineral factor to be carbonated apatite. The peak wave numbers of the main mineral and matrix components were nearly identical to those originally reported by Tarnowski et al. (2002), as shown in Fig. 1 and Table 1.

We next compared the mineral-to-matrix ratios in the bone samples for all six experimental groups based on the Raman spectral analysis results. All three mineral-matrix ratios, $v 1$ /amide I, $v 1 /$ amide III, and $v 1 / \mathrm{CH}_{2}$, were significantly decreased in the 60 and $80^{\circ} \mathrm{C}$ treatment groups $(P<0.05)$ (Fig. $2 \mathrm{a}-\mathrm{c}$, respectively). The $v 1 / \mathrm{CO}_{3}$ ratio also tended to be lower in the 60 and $80^{\circ} \mathrm{C}$ treatment groups (Fig. 2e). No differences in the hydroxyproline/proline ratio were observed between the Fresh and other five treatment groups (Fig. 2d). The crystallinity of bones in the Radi group was significantly higher than that of bones in the Fresh group (Fig. 2f).

\section{Discussion}

Using confocal laser Raman spectroscopy, we evaluated rat femoral bones after being subjected to procedures routinely used for the preservation and sterilization of allografts. We found that although heat treatment and irradiation resulted in altered Raman
Table 1 Raman spectroscopy results for rat cortical bone between 350 and $1,750 \mathrm{~cm}^{-1}$

\begin{tabular}{ll}
\hline Raman shift $\left(\mathrm{cm}^{-1}\right)$ & Assignment \\
\hline $1,716-1,541$ & Amide I \\
$1,446-1,455$ & $\mathrm{CH}_{2}$ wag \\
$1,298.1-1,214.4$ & Amide III \\
$1,087.9-1,052.1$ & $\mathrm{CO}_{3}^{2-} v_{1}$, type B carbonate \\
& substitution \\
$981.9-925.7$ & $\mathrm{PO}_{4}^{3-} v_{1}$ \\
$631.0-545.8$ & $\mathrm{PO}_{4}^{3-} v_{4}$ \\
\hline
\end{tabular}

spectra, freeze-thawing had no detectable effects on the composition of bone minerals or matrix. This finding suggests that Raman spectroscopy would be useful for quality assessment of allograft bones after processing and sterilization procedures.

The freezing of tissues at $-80^{\circ} \mathrm{C}$ is generally used for long-term preservation in tissue banks and is also considered to reduce the immunogenicity of allografts (Gitelis and Cole 2002; Heyligers and KleinNulend 2005; Weyts et al. 2003). However, repeated freeze-thawing may affect the properties of tissue; compared to a single freeze-thaw treatment, the repeated freeze-thawing of tissues, including the palate, liver, and skin, produces more extensive and thorough tissue destruction (Gage and Baust 1998). In present study, no notable changes in any Raman spectra were observed in the FT1 and FT3 treatment groups, and even repeated freeze-thawing did not affect the Raman spectra of femur samples. This finding suggests that the freeze-thaw procedure for bone preservation may not affect collagen structure. Our results are consistent with those of Voggenreiter et al. (1994), who examined the effects of preservation and sterilization on cortical bone grafts using SEM and found that compared to fresh bone, cryopreservation and irradiation had no deleterious effects on the bone surface structure compared to fresh, untreated bone. In addition, in a previous study, we did not observe significant differences in the fibril occupation ratio or cycle length of intr aperiodic bands of collagen fibrils between the control and freeze-thawed tendons (Park et al. 2009). Taken together with the results of our present study, these findings suggest that the freeze-thaw cycle does not affect collagen structure.

To avoid the transmission of bacteria, human immunodeficiency virus, and hepatitis $\mathrm{C}$ virus during 
Fig. 1 Typical Raman spectra of cortical bone for each treatment group. $a$ Fresh group, $b$ FT1 group, $c$ FT3 group, $d 60^{\circ} \mathrm{C}$ group, $e 80^{\circ} \mathrm{C}$ group, and $f$ radi group. Peaks corresponding to the assignments listed in Table 1 are indicated.

Raman intensity is shown in arbitrary units (a.u.)
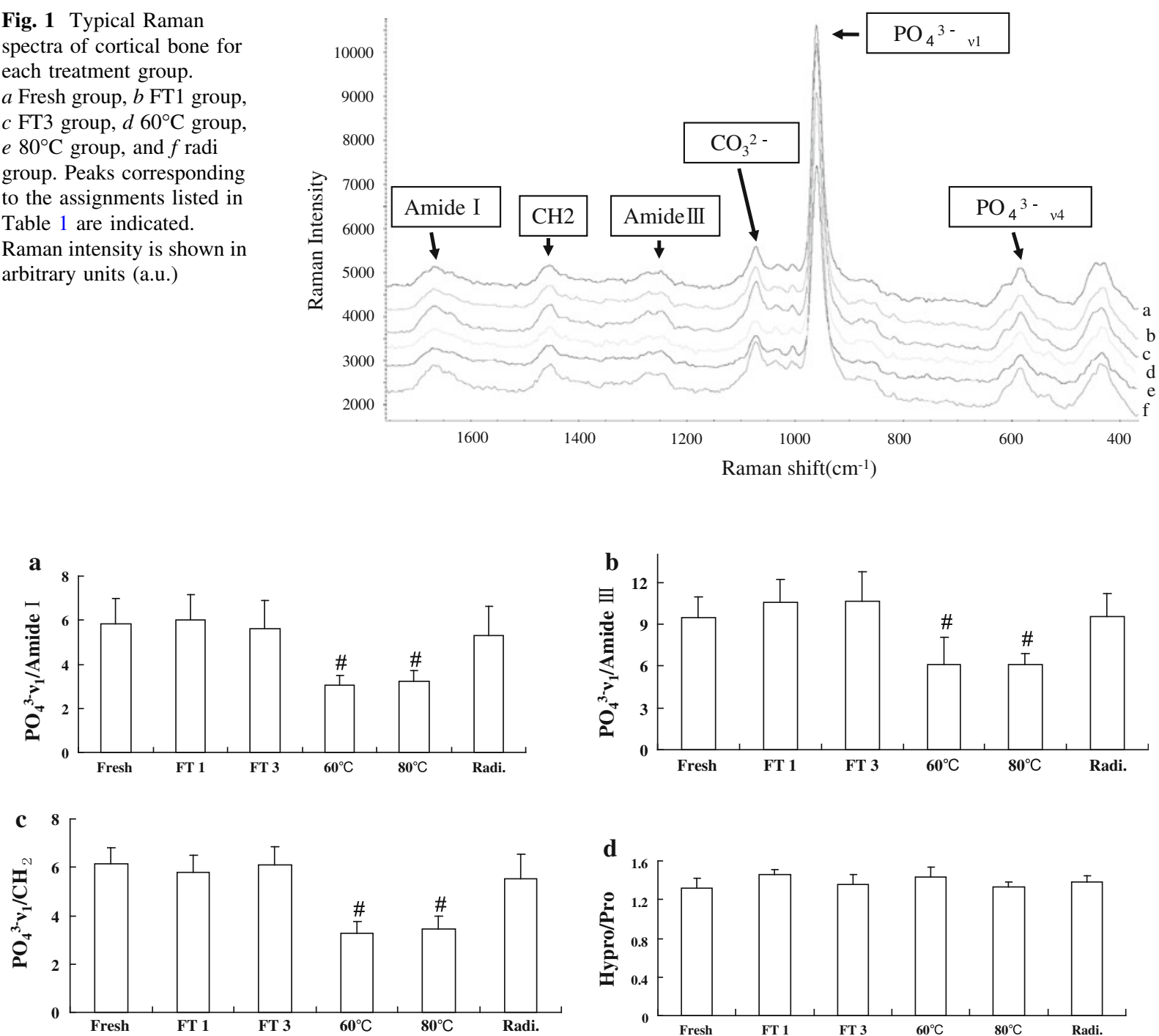

d
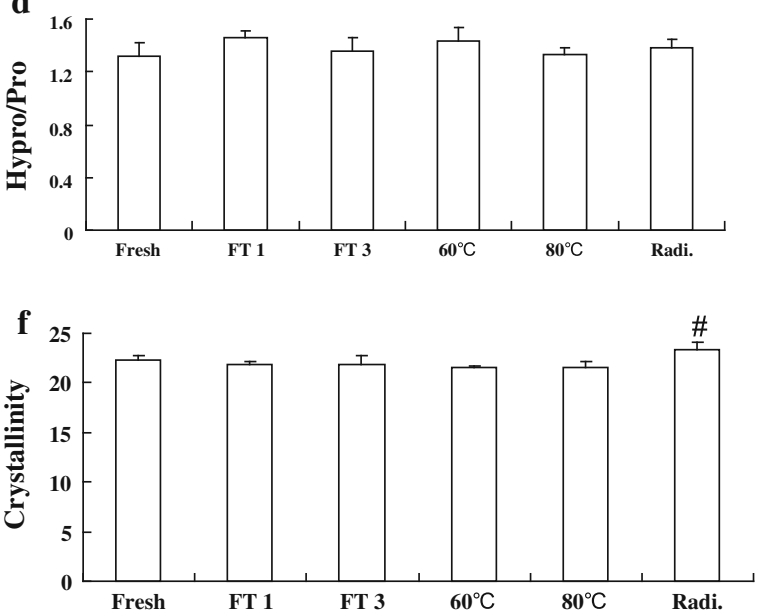

are presented as the mean $\pm \mathrm{SD}$. One-way analysis of variance (ANOVA) was followed by Tukey's HSD post-hoc multiple comparison test. ${ }^{\#} P<0.05$ versus the fresh group

Orthopaedics Association (1999). Knaepler et al. (1991) reported that osteoinduction properties and mechanical strength of bone were preserved at 
temperatures lower than $80^{\circ} \mathrm{C}$. Similarly, Izawa et al. (2001) demonstrated that bone morphogenetic proteins and osteoinduction potential are preserved after heat treatment at $60^{\circ} \mathrm{C}$ for $10 \mathrm{~h}$, indicating that the quality of heat-treated bone is adequately retained. However, Kühne et al. (1992) reported that deepfrozen allografts more rapidly integrated than allografts subjected to moderate heat-treated treatment. In our present study, Raman spectroscopic analysis revealed that the mineral-to-matrix ratios, namely $v 1 /$ Amide I, $v 1 /$ Amide III, and $v 1 / \mathrm{CH}_{2}$, were significantly decreased in bone of the 60 and $80^{\circ} \mathrm{C}$ treatment groups. Otomo et al. (2004) also reported a decrease of mineral-matrix ratios in the bone of ovariectomized rats (Otomo et al. 2004). Our finding of lowered mineral-to-matrix ratios following heat treatment indicates that the decreased quality of heated bones may also explain the slower integration period often observed for heat-treated allografts (Kühne et al. 1992).

Gamma irradiation from cobalt-60 sources, which has been widely used to terminally sterilize bone allografts, is well known to adversely affect the mechanical and biological properties of bone allografts in a dose-dependent manner (Nguyen et al. 2007). The mechanical properties of allograft bone markedly decrease when the gamma dose is increased above 25 or $60 \mathrm{kGy}$ for cortical and cancellous bone, respectively (Nguyen et al. 2007). Tissue banks operating in countries that were using the ionizing radiation technique for the sterilization of tissues, particularly in Asia and the Pacific and in the Latin American regions, used a target dose of $25 \mathrm{kGy}$ (Pedraza et al. 2011). They tried to follow ISO 11137 (IAEA 2007) and ISO/TR 13409 ISO/TR 13409(1996) to validate the process (Pedraza 2006). Therefore, this dose is most frequently used for sterilization treatment by tissue banks, although opinions are divided as to the optimal dose. In our present study, the use of $25 \mathrm{kGy}$ gamma irradiation did not change the resulting Raman spectrum of treated femurs, but did increase the crystallinity. A previous study reported that the crystallinity of human bone increases with aging (Hanschin and Stern 1995). Yerramshetty and Akkus (2008) also demonstrated that tissue strength and stiffness increased with increasing crystallinity, whereas the ductility reduced. Thus, increased crystallinity in irradiated allograft bone may represent an adverse effect of irradiation sterilization methods.
However, Jinno et al. (2000) reported that the irradiation process did not consistently or significantly affect the incorporation of syngeneic or allogeneic grafts. Therefore, changes in the crystallinity of bone may have little effect on the incorporation of syngeneic or allogeneic grafts.

Several studies have reported that Raman spectroscopy is useful for the evaluation of bone quality, which is the combined function of various patients characteristics, including age, and disease status, such as osteoporosis or osteoarthritis (Ager et al. 2005; Akkus et al. 2004; Krafft et al. 2009; Otomo et al. 2004). However, the bone quality of allograft bones after processing and sterilization procedures are not routinely evaluated because standard techniques, including mechanical testing and bone graft models, are time consuming and often lead to the destruction of the sample. We found that the freeze-thaw process did not affect the resulting Raman spectrum. As Raman spectroscopy allows the rapid evaluation of allograft bone quality without complicated tissue preparation, this approach may allow the quality control of allograft bones after sterilization procedures. Notably, we found that sterilization processes, particularly heating and gamma irradiation altered the Raman spectrum of femoral bones, suggesting that these treatment processes change the quality of bone allografts. Our analyses also suggest that Raman spectroscopy may be useful for the evaluation of bone sterilization techniques.

Acknowledgments This investigation was supported in part by Grants-in-Aid from the Ministry of Science, Education and Culture of Japan to Kentaro Uchida and Kouji Naruse, by Grants-in-Aid from the Ministry of Health, Labour and Welfare for Research on the Human Genome, Tissue Engineering and Food Biotechnology to Moritoshi Itoman, and a Parents' Association grant from Kitasato University School of Medicine, a research grant from SDS, Inc., and a research grant from The Nakatomi Foundation to Kouji Naruse.

Open Access This article is distributed under the terms of the Creative Commons Attribution Noncommercial License which permits any noncommercial use, distribution, and reproduction in any medium, provided the original author(s) and source are credited.

\section{References}

Ager JW, Nalla RK, Breeden KL, Ritchie RO (2005) Deepultraviolet Raman spectroscopy study of the effect of 
aging on human cortical bone. J Biomed Opt 10:034012. doi:10.1117/1.1924668

Akkus O, Adar F, Schaffler MB (2004) Age-related changes in physicochemical properties of mineral crystals are related to impaired mechanical function of cortical bone. Bone 34:443-453. doi:10.1016/j.bone.2003.11.003

Anderson MJ, Keyak JH, Skinner HB (1992) Compressive mechanical properties of human cancellous bone after gamma irradiation. J Bone Jt Surg Am 74:747-752. doi: $10.1117 / 1.429994$

Carden A, Morris MD (2000) Application of vibrational spectroscopy to the study of mineralized tissues (review). J Biomed Opt 5:259-268

Currey JD, Foreman J, Laketic I, Mitchell J, Pegg DE, Reilly GC (1997) Effects of ionizing radiation on the mechanical properties of human bone. J Orthop Res 15:111-117. doi: 10.1002/jor. 1100150116

Freeman JJ, Wopenka B, Silva MJ, Pasteris JD (2001) Raman spectroscopic detection of changes in bioapatite in mouse femora as a function of age and in vitro fluoride treatment. Calcif Tiss Int 68:156-162. doi:10.1007/s002230001206

Gage AA, Baust J (1998) Mechanisms of tissue injury in cryosurgery. Cryobiology 37:171-186. doi:10.1006/cryo. 1998.2115

Gitelis S, Cole BJ (2002) The use of allografts in orthopaedic surgery. Instr Course Lect 51:507-520

Hamer AJ, Strachan JR, Black MM, Ibbotson CJ, Stockley I, Elson RA (1996) Biochemical properties of cortical allograft bone using a new method of bone strength measurement. A comparison of fresh, fresh-frozen and irradiated bone. J Bone Jt Surg Br 78:363-368

Hanschin RG, Stern WB (1995) X-ray diffraction studies on the lattice perfection of human bone apatite (Crista iliaca). Bone 16:355S-363S. doi:10.1016/S8756-3282(95) 80385-8

Heyligers IC, Klein-Nulend J (2005) Detection of living cells in non-processed but deep-frozen bone allografts. Cell Tiss Bank 6:25-31. doi:10.1007/s10561-005-1089-4

IAEA (2007) Radiation sterilisation of tissue allografts: requirements for validation and routine control: a code of practice. STI/PUN/1307. IAEA, Vienna

ISO/TR 13409 (1996) Sterilisation of health care products: radiation sterilisation: substations of $25 \mathrm{kGy}$ as sterilisation dose for small or infrequent production batches. International Organisation for Standardisation, Geneva

Izawa H, Hachiya Y, Kawai T, Muramatsu K, Narita Y, Ban N, Yoshizawa H (2001) The effect of heat-treated human bone morphogenetic protein on clinical implantation. Clin Orthop Relat Res 390:252-258

Japanese Orthopaedic Association (1999) The guideline about an orthopedics transplant and a frozen bone bank manual. Japanese Orthopaedic Association, Tokyo, pp 115-144
Jinno T, Miric A, Feighan J, Kirk SK, Davy DT, Stevenson S (2000) The effects of processing and low dose irradiation on cortical bone grafts. Clin Orthop Relat Res 375:275-285

Knaepler H, Haas H, Puschel HU (1991) Biomechanical properties of heat and irradiation treated spongiosa. Unfallchirurgie 17:194-199

Krafft C, Steiner G, Beleites C, Salzer R (2009) Disease recognition by infrared and Raman spectroscopy. J Biophoton 2:13-28. doi:10.1002/jbio.200810024

Kühne JH, Bartl R, Hammer C, Refior HJ, Jansson V, Zimmer M (1992) Moderate heat treatment of bone allografts. Experimental results of osteointegration. Arch Orthop Trauma Surg 112:18-22. doi:10.1007/BF00431038

Nguyen H, Morgan DA, Forwood MR (2007) Sterilization of allograft bone: effects of gamma irradiation on allograft biology and biomechanics. Cell Tiss Bank 8:93-105. doi: 10.1007/s10561-006-9020-1

Otomo H, Sakai A, Ikeda S, Tanaka S, Ito M, Phipps RJ, Nakamura T (2004) Regulation of mineral-matrix ratio of lumbar trabecular bone in ovariectomized rats treated with risedronate in combination with or without vitamin $\mathrm{K} 2$. J Bone Miner Metab 22:404-414. doi:10.1007/s00774004-0502-6

Park HJ, Urabe K, Naruse K, Onuma K, Nemoto N, Itoman M (2009) The effect of cryopreservation or heating on the mechanical properties and histomorphology of rat bonepatellar tendon-bone. Cell Tiss Bank 10:11-18. doi: 10.1007/s10561-008-9109-9

Pedraza JM (2006) The IAEA program on tissue banking. A successful program for developing countries. Cell Tiss Bank 7:237-258. doi:10.1007/s10561-006-9011-2

Pedraza JM, Yusof N, Hilmy N (2011) A Review of the international atomic energy agency (IAEA) code of practice for the radiation sterilisation of tissue allografts. J Cell Sci Ther 2:1-5. doi:10.4172/2157-7013.1000105

Tarnowski CP, Ignelzi MA Jr, Morris MD (2002) Mineralization of developing mouse calvaria as revealed by Raman microspectroscopy. J Bone Miner Res 17:1118-1126. doi: 10.1359/jbmr.2002.17.6.1118

Voggenreiter G, Ascherl R, Blumel G, Schmit-Neuerburg KP (1994) Effects of preservation and sterilization on cortical bone grafts. A scanning electron microscopic study. Arch Orthop Trauma Surg 113:294-296. doi:10.1007/BF0044 3821

Weyts FA, Bos PK, Dinjens WN, van Doorn WJ, van Biezen FC, Weinans H, Verhaar JA (2003) Living cells in 1 of 2 frozen femoral heads. Acta Orthop Scand 74:661-664

Yerramshetty JS, Akkus O (2008) The associations between mineral crystallinity and the mechanical properties of human cortical bone. Bone 42:476-482. doi:10.1016/ j.bone.2007.12.001 